Reply

\title{
Reply to Gambazza et al. Cystic Fibrosis, New Frontier: Exploring the Functional Connectivity of the Brain Default Mode Network. Comment on "Elce et al. Impact of Physical Activity on Cognitive Functions: A New Field for Research and Management of Cystic Fibrosis. Diagnostics 2020, 10, 489"
}

\author{
Ausilia Elce ${ }^{1,2, *(\mathbb{D})}$, Valentina Elce ${ }^{3}$ and Alessandro Del Pizzo ${ }^{4}$ (D) \\ 1 CEINGE Biotecnologie Avanzate SCarl, Via Gaetano Salvatore 486, 80145 Napoli, Italy \\ 2 Dipartimento di Scienze Umanistiche, Università Telematica Pegaso, Via Porzio, Centro Direzionale, \\ isola F2, 80143 Napoli, Italy \\ 3 MoMiLab, IMT School for Advanced Studies, Piazza San Francesco 19, 55100 Lucca, Italy; \\ valentina.elce@imtlucca.it \\ 4 Dipartimento di Fisica, University of Pisa, Largo Bruno Pontecorvo, 3, 56127 Pisa, Italy; \\ aledelpizzo@gmail.com \\ * Correspondence: ausilia.elce@unipegaso.it
}

check for

updates

Citation: Elce, A.; Elce, V.; Pizzo,

A.D. Reply to Gambazza et al. Cystic Fibrosis, New Frontier: Exploring the Functional Connectivity of the Brain Default Mode Network. Comment on "Elce et al. Impact of Physical Activity on Cognitive Functions: A New Field for Research and Management of Cystic Fibrosis. Diagnostics 2020, 10, 489". Diagnostics 2021, 11, 1002. https://doi.org/10.3390/ diagnostics11061002

Academic Editor: Mattia Gentile

Received: 17 May 2021

Accepted: 26 May 2021

Published: 31 May 2021

Publisher's Note: MDPI stays neutral with regard to jurisdictional claims in published maps and institutional affiliations.

Copyright: (c) 2021 by the authors. Licensee MDPI, Basel, Switzerland. This article is an open access article distributed under the terms and conditions of the Creative Commons Attribution (CC BY) license (https:/ / creativecommons.org/licenses/by/ $4.0 /)$.
We appreciate the interest in our review and we are grateful for the comment by Gambazza S. et al., because it investigates new aspects of functional connectivity in CF patients, applying fMRI to resting state study for neuropsychological assessment in trained CF subjects.

The preliminary results seem to be very encouraging and require further research to assess the specific exercise-induced modifications of CF patient's cognitive functions. The topic falls in the new field of research for CF management proposed by our review. A progression in this field may be a turning point for the approach to Cystic Fibrosis patients from the earliest interventions.

In the last year, a limited number of studies focusing on CF neurocognitive aspects were published. In 2020, Gold A et al. observed improvements in verbal learning, aspects of mood, behaviour, and adaptive functioning in a group of children (CF and non-CF) undergoing lung transplantation, although a weakness of executive functions was also observed after transplantation [1]. These data suggest that further studies are required to investigate specific CF cerebral connectivity and that educational and neuropsychological strategies should be adopted to prevent the cognitive alterations observed in CF patients.

Conflicts of Interest: The authors declare no conflict of interest.

\section{Reference}

1. Gold, A.; Young, J.M.; Solomon, M.; Grasemann, H. Neuropsychological outcomes following pediatric lung transplantation. Pediatr. Pulmonol. 2020, 55, 2427-2436. [CrossRef] [PubMed] 